observed when the drop was attributed entirely to loss of convective heat. For males, the most pronounced change in thermoregulation was in skin moisture and TEWL, suggesting a greater thermal load from SRH exposure in males that required water evaporation from the skin to regain thermal balance.

Conclusions The exposure to SRH presented unique influences to core metabolism and thermoregulation compared to those from exposure to convective heat. Adequate clothing protecting against temperature step and the residual influence of SRH was necessary in thermal transient.

\section{CALIFORNIA HEAT ILLNESS PREVENTION STUDY (CHIPS) IN IMMIGRANT LATINO FARM WORKERS}

'B Schenker, 'Mitchell, 'Wadsworth, 'Jones. 'University California, Davis, Davis, United States of America; ${ }^{2}$ California Institute for Rural Studies, Davis, California, United States of America

\subsection{6/oemed-2013-101717.385}

Objectives To quantify the contributions of work intensity and ambient heat to the risk of heat illness in field labourers working with diverse crops.

Methods Field workers were assessed throughout a single daytime work shift. Body weight and blood osmolality changes, continuous heart rate and core body temperature (using ingested telemetry) were recorded. Personal and stationary (area) ambient air temperature and relative humidity were measured using individual data loggers and weather stations. Workers were questioned about their current and historical experiences with field work in the heat.

Results One-hundred workers were assessed between late June and August 2012 on seven farms in the California Central Valley. Thirteen were female, mean age was $36.8(\mathrm{SD}=11.9)$ years. Ninety-four percent were born in Mexico, the remainder in the USA, and over $95 \%$ of the workers identified as Latino. Educational level was low; $47 \%$ had attended $\leq 6$ years of school. Twenty-two percent lost over $1.5 \%$ of their original body weight (ACGIH suggested criteria for increased risk of dehydration), $80.2 \%$ increased serum osmolality, with $21 \%$ increasing $\geq 3 \%$. Males lost significant weight $(-0.56 \mathrm{~kg}, 95 \% \mathrm{CI}-0.40$ to -0.73 $\mathrm{kg})$ as did those whose blood osmolality increased $(-0.59 \mathrm{~kg}$, 95\% CI -0.34 to $-0.85 \mathrm{~kg}$ ). Associations will be assessed between heart rate, task, crop, ambient conditions and core body temperature.

Conclusions Field workers exhibited reduced hydration status over their work shift. Combined physiological and survey data may allow susceptibility to heat illness in summertime agricultural workers to be quantified.

\section{ANNOYANCE FROM OCCUPATIONAL NOISE: THE IMPACT} OF EXPOSURE LEVEL AND HEARING PROTECTION

${ }^{1}$ A Kolstad, 'Stokholm, 'Vestergaard, ${ }^{1}$ Frederiksen, ${ }^{2}$ Hansen, ${ }^{3}$ Lund, ${ }^{3}$ Kristiansen, ${ }^{1}$ Christensen, ${ }^{4}$ Wetke, ${ }^{5}$ Bonde. 'Aarhus University Hospital, Aarhus C, Denmark; ${ }^{2}$ Copenhagen University, Copenhagen, Denmark; ${ }^{3}$ The National Research Centre for the Working Environment, Copenhagen, Denmark; ${ }^{4}$ Odense University Hospital, Odense, Denmark; ${ }^{5}$ Bispebjerg Hospital, Copenhagen, Denmark

\subsection{6/oemed-2013-101717.386}

Objectives. Annoyance from transportation noise is well characterised but little is known about occupational noise. We investigated the relation between occupational noise exposure level, the use of hearing protection devices (HPD), and noise annoyance.
Methods We studied 452 industrial workers and 68 financial workers who post shift reported noise annoyance during work on a 5 -point scale. Noise exposure level was recorded every 5 seconds at the dominant shoulder for 24 hours and we calculated the $\mathrm{L}_{\mathrm{Aeq}}$ value for work hours. For 342 workers who kept a HPD diary, we subtracted $10 \mathrm{~dB}$ from every noise recording obtained during HPD use and estimated the $\mathrm{L}_{\mathrm{AEq}}$ value at the ear.

Results The mean measured noise exposure level was $80.0 \mathrm{~dB}$ (A) [range: 55.0-98.9] and the mean estimated level at the ear $77.8 \mathrm{~dB}(\mathrm{~A})$ [range: 55.0-94.2]. Fifty-one percent of workers exposed at a measured noise level $\geq 85 \mathrm{~dB}(\mathrm{~A})$ were annoyed (the upper 3 points on the annoyance scale) and 14\% highly annoyed (the upper 2 points). In a logistic regression model that also adjusted for neuroticism, annoyance increased monotonously with $6 \%$ per $\mathrm{dB}(\mathrm{A})(\mathrm{OR}=1.06,95 \%$ CI 1.02-1.09). A slightly lower trend was seen per estimated $\mathrm{L}_{\mathrm{AEq}}$ level at the ear $(\mathrm{OR}=1.04,95 \%$ CI $0.99-1.07)$. HPD use was strongly associated with annoyance when adjusted for noise exposure level (OR 2.3, 95\% CI 1.3-3.9).

Conclusions Increasing occupational noise exposure level was associated with increasing prevalence of annoyance but at a much lower annoyance level than seen for transportation noise. We documented no gainful effect of hearing protection, but the opposite. An obvious explanation is that noise annoyance is not solely a question of the amount of noise appearing at the ear but also other characteristics of a noisy work environment; furthermore, that HPD use is predicted by noise sensitivity and other individual characteristics that are associated with noise annoyance.

\section{EXPOSURE TO PARTICLES AND NOISE DURING HIGHWAY MAINTENANCE WORK AND ASSOCIATED SHORT-TERM CARDIOVASCULAR HEALTH EFFECTS}

${ }^{1} \mathrm{R}$ M Meier, ${ }^{2}$ Cascio, ${ }^{2}$ Ghio, ${ }^{1}$ Danuser, ${ }^{1}$ Riediker. ${ }^{1}$ Institute for Work and Health, University of Lausanne, Lausanne, Switzerland; ' ${ }^{2}$ National Health and Environmental Effects Research Laboratory, US EPA, Research Triangle Park, NC, United States of America

\subsection{6/oemed-2013-101717.387}

Objectives Highway maintenance workers are exposed to elevated particle and noise levels during their work. Exposure to particles as well as to noise has been linked to cardiovascular diseases. Thus, this worker population may be at higher cardiovascular risk. With our study we aimed to provide a better understanding of the workers' exposure and to assess associated short-term health effects.

Methods We monitored the particle and noise exposure of 18 road maintenance workers during five repeated, non-consecutive work shifts and measured health endpoints including blood pressure, selected blood markers for inflammation and thrombosis, continuous ECG as well as lung function and exhaled nitric oxide (FeNO).

Results The workers' exposure to particles and noise was variable between work shifts and depended on work activities. Fine particle $\left(\mathrm{PM}_{2.5}\right)$ mass concentrations over full work shifts ranged from $20.3 \mu \mathrm{g} / \mathrm{m}^{3}$ to $321 \mu \mathrm{g} / \mathrm{m}^{3}$. Particle number concentrations were between $1.6 \mathrm{E} 4$ particles $/ \mathrm{cm}^{3}$ and $4.1 \mathrm{E} 5$ particles $/ \mathrm{cm}^{3}$. Averaged noise levels were frequently above $85 \mathrm{~dB}[\mathrm{~A}]$, ranging from $73.3 \mathrm{~dB}[\mathrm{~A}]$ to $99.6 \mathrm{~dB}[\mathrm{~A}]$. The 17 subjects included for health assessments had an average age of 45.2 years (SD 7.6) and a BMI of $26.6 \mathrm{~kg} / \mathrm{m}^{2}$ (2.6). Average systolic/diastolic blood 